\title{
ELECTROCHEMICAL SYNTHESIS OF NANODISPERSE COPPER(I) OXIDE USING ALTERNATING CURRENT
}

\author{
Aizhan Mamyrbekova ${ }^{1}$, Aigul Mamyrbekova ${ }^{1, 凶}$, M.K. Kassymova ${ }^{2}$, \\ Zh. Aitbayeva ${ }^{3}$, G.E. Shimirova ${ }^{4}$, Zh. E. Daribayev ${ }^{5}$ and D. Tanatar ${ }^{6}$ \\ ${ }^{1}$ Department of Laboratory Disciplines, Faculty of Dentistry, Khoja Akhmet Yassawi \\ International Kazakh-Turkish University, 29, B. Sattarkhanov Ave., Turkestan-161200, \\ Kazakhstan \\ ${ }^{2}$ Department of Chemistry, Natural Scientific and Pedagogical Higher School, Auezov South \\ Kazakhstan University, 5, Tauke khan Ave., Shymkent-160012, Kazakhstan \\ ${ }^{3}$ Department of Food Engineering, Textile and Food Engineering Higher School, \\ Auezov South Kazakhstan University, 5, Tauke khan Ave., Shymkent-160012, Kazakhstan \\ ${ }^{4}$ Technical department, PetroKazakhstan Oil Products LLP, Yenbekshi District, Quarter 264, \\ Shymkent-160011, Kazakhstan \\ ${ }^{5}$ Department of Ecology and Chemistry, Faculty of Natural Science, Khoja Akhmet Yassawi \\ International Kazakh-Turkish University, 29, B. Sattarkhanov Ave., Turkestan-161200, \\ Kazakhstan \\ ${ }^{6}$ Student of group 203, Faculty of Dentistry, Khoja Akhmet Yassawi International Kazakh- \\ Turkish University, 29, B. Sattarkhanov Ave., Turkestan-161200, Kazakhstan \\ ${ }^{\square}$ Corresponding Author: aigul.mamyrbekova@ayu.edu.kz
}

ABSTRACT

The possibility of obtaining nano dispersed copper(I) oxide by electrolysis on the alternating current of industrial frequency is shown. The parameters of electrolysis, influencing the electrochemical oxidation of copper in neutral solutions and the rate of formation of the copper(I) oxide powder, were studied. A comprehensive study of copper(I) oxide powders obtained by electrosynthesis using modern physicochemical methods (electron microscopy, X-ray phase analysis, IR spectroscopy and thermogravimetry) was carried out, which made it possible to establish their qualitative composition and particle sizes that make up these compounds. By varying the concentration of the electrolyte, the current density at relatively low electrolysis temperatures, nanodispersed powders with a high specific surface area and particle sizes of 5-30 nm were obtained.

Keywords: Electrolysis, Alternating Current, Copper Oxides, Nanodispersed Powder, Oxidation Rate.

RASĀYAN J. Chem., Vol. 14, No.3, 2021

\section{INTRODUCTION}

In recent years, there has been an active introduction of electronics into all spheres of human activity, accompanied by the creation of new electronic devices, their miniaturization and autonomization. The development of areas such as sensor technology, optoelectronics (display technologies) is impossible without the creation of new materials that meet increasing requirements. One of the promising materials for future generations of micro-, nanoelectronic and sensor technology are metal oxides..$^{1-3}$ Currently, there are a large number of methods for producing materials based on metal oxides. Of particular interest are methods that make it possible to obtain highly dispersed products: electrochemical, gas-phase plasmachemical, mechanochemical, high-temperature synthesis. ${ }^{4-6}$

Electrochemical synthesis of metal oxides using non-stationary modes makes it possible to obtain metal oxides with a nominal diameter of primary particles in the range of $10^{-9}$ to $10^{-6} \mathrm{~m}$. The products obtained by this method are quite different from the products obtained by other chemical and physical methods. The oxides obtained by electrochemical synthesis have several advantages, such as highly developed surface and dispersion of the material, the presence of a large number of mesopores, and also the 
minimum content of impurities in the synthesis products. ${ }^{7-9}$ One of the most important advantages of the electrochemical method is the possibility of obtaining ultrapure metal oxides. Also, the practical value of the method is increased by the fact that the regulation of the parameters of electrochemical synthesis makes it possible to produce powders with a given dispersion. Of particular relevance among the variety of methods is finding fairly simple economical and environmentally friendly methods for the synthesis of nano- and micro-sized dispersed materials based on copper oxides. The study of the electrochemical dissolution of metals under nonstationary conditions becomes relevant with the development of modern trends in domestic science associated with the development of high-tech multifunctional materials based on metal oxide nanopowders. ${ }^{10,11}$

A small number of works are devoted to the question of electrochemical synthesis of metal oxides using alternating current. Scientists have studied the effect of the composition and concentration of the electrolyte, current density and electrolysis temperature on the oxidation rate of metals $(\mathrm{Cu}, \mathrm{Cd}, \mathrm{Ti}, \mathrm{Zn}$, $\mathrm{Sn}, \mathrm{Ni}, \mathrm{Al}, \mathrm{Pb}, \mathrm{Fe}, \mathrm{Mo}$ ) during polarization with alternating current with a frequency of $50 \mathrm{~Hz} .{ }^{12-15} \mathrm{The}$ electrochemical oxidation and dispersion of electrodes in a sodium chloride solution to obtain copper(I) oxide under the action of a symmetric or asymmetric alternating pulse current with a frequency of $50 \mathrm{~Hz}$ was studied. ${ }^{16}$ The possibility of obtaining copper oxides with a high specific surface area by electrolysis of metallic copper using an alternating current of industrial frequency is shown. The parameters influencing the rate of formation of oxides were studied. The phase composition and characteristics of the porous structure of electrosynthesis products were determined depending on the modes of the process. ${ }^{17}$

Of particular interest are the works of scientists studying copper(I) oxide, which has high thermal conductivity, electrical conductivity, optical characteristics, antibacterial and fungicidal properties, which has become the object of study of nanotechnological research. In the transition to the nanoscale, the above properties, previously manifested at the microlevel, are significantly enhanced. ${ }^{18}$ Despite such a significant amount of research on the electrosynthesis of metal oxides under nonstationary conditions, there are few works on the production of copper oxides using alternating current. The use of alternating current for the implementation of the electrochemical process presents a unique opportunity for the synthesis of nanodispersed materials based on metal oxides. At the same time, there is no information in the literature on the preparation of such materials by this method; therefore, studies in the field of electrochemical synthesis of copper(I) oxide using an alternating current of industrial frequency are relevant.

The work purpose was to synthesize nanodispersed copper(I) oxide by electrolysis under nonstationary conditions in neutral solutions, to study the phase composition of the electrosynthesis product of copper(I) oxide.

\section{EXPERIMENTAL}

\section{Method of Carrying out Electrolysis by Alternating Current}

The proposed method for producing nanodispersed copper oxides is based on the electrochemical oxidation of metal electrodes in neutral solutions under the action of asymmetric alternating current of industrial frequency of $50 \mathrm{~Hz}$. Two identical copper plate electrodes with an area of $\mathrm{S}=15 \mathrm{~cm}^{2}$ were placed in electrolyte solutions and an alternating current was passed with constant stirring. During the experiment, technological parameters such as current density values, temperature, electrolysis time, and electrolyte concentration were varied to obtain powders with high dispersion. ${ }^{19}$

The electrolyte used was $\mathrm{NaCl}$ solutions in the concentration range of 1-5 mol/L. The electrolysis was carried out at temperatures of $50-60{ }^{\circ} \mathrm{C}$ and a current density of $0.5-2.5 \mathrm{~A} / \mathrm{cm}^{2}$. The resulting suspensions of composite materials were filtered, repeatedly flushed with bidistilled water, with further processing under the influence of electromagnetic radiation (EMR). The power of electromagnetic radiation is 200$2500 \mathrm{~W}$, the radiation frequency is $2.5 \mathrm{GHz}$, the processing time is $5-25$ minutes. $^{20}$

The use of EMP instead of the stages of drying and heat treatment makes it possible to carry out a uniform distribution of radiation on copper(I) oxide samples throughout the entire volume, which significantly affects the qualitative and dimensional characteristics of copper(I) oxide powders.

The rate of formation of copper(I) oxide was determined from the rate of weight loss of electrodes per unit time. During the electrolysis, the main parameters were monitored: the values of the current density and voltage on the electrolyzer, the temperature, and the changes in the potentials of both electrodes over 
time were recorded. The potentials were measured relative to a saturated silver chloride reference electrode. $^{21}$

\section{Physicochemical Methods Study of Copper(I) Oxide Powders}

The structure of the resulting sediments was studied by electron microscopy. An ISM-6490LV scanning electron microscope with an INCA Energy dispersive microanalysis system was used in the work. X-ray phase analysis was performed on a DRON-3M device with automatic recording of X-ray diffraction patterns. The specific surface area of copper(I) oxide samples was determined by the Brunauer-EmmettTeller (BET) method with low-temperature adsorption argon on a helium-argon mixture on a Tsvet 211 sorbtometer. Thermogravimetric studies of copper(I) oxide powder was carried out on the «TG $209 \mathrm{~F} 1$ Micro-thermobalance» in the temperature range of 20 to $960{ }^{\circ} \mathrm{C}$. The sample heating rate is $10 \mathrm{~K} / \mathrm{min}$. The powders were heated in an atmosphere of air and an atmosphere of argon. ${ }^{22}$

IR transmission spectra were obtained using a Shimadzu IR Prestige 21 Fourier Transform Infrared (FTIR) Spectrophotometer equipped with a disturbing total internal reflection attachment in the wavenumber range of $4000-600 \mathrm{~cm}^{-1}$ with a resolution of $4 \mathrm{~cm}^{-1}$.

\section{RESULTS AND DISCUSSION}

The study of the kinetics of the process of electrosynthesis of highly dispersed copper(I) oxide by electrolysis using an alternating current of industrial frequency makes it possible to determine the rate of copper oxidation by varying the electrolysis process parameters.

To reveal the regularities of the electrosynthesis of copper(I) oxide powders, the influence of sodium chloride concentration of $1-5 \mathrm{~mol} / 1$, the current density of $0.5-2.5 \mathrm{~A} / \mathrm{cm}^{2}$ and temperature in the range of 40-60 ${ }^{\circ} \mathrm{C}$ was studied.

In contrast to DC electrolysis, when using a non-stationary electrolysis mode, the polarity of the electrodes changes with time at a given frequency, at a frequency of $50 \mathrm{~Hz}$, the polarity of the electrodes changes 50 times per second, that is, oxidation and reduction processes take place on the same electrode.

Copper oxidation occurs in two stages since the direct transition $\mathrm{Cu}^{0} \rightarrow \mathrm{Cu}^{2+}$ requires overcoming the energy barrier. The limiting stage of the copper oxidation process is copper oxidation according to the reaction ${ }^{23}$ :

$$
\mathrm{Cu}^{0}-\mathrm{e}^{-} \rightarrow \mathrm{Cu}^{+}
$$

Due to the rapid recharging of the electrode surface during the process using alternating current, the second stage of the copper oxidation process does not have time to proceed:

$$
\mathrm{Cu}^{+}-\mathrm{e}^{-} \rightarrow \mathrm{Cu}^{2+}
$$

Copper ions in an aqueous solution interact by the following reactions:

$$
\begin{aligned}
2 \mathrm{Cu}^{+}+\mathrm{e}^{-}+\mathrm{H}_{2} \mathrm{O} & \rightarrow \mathrm{Cu}_{2} \mathrm{O}+\mathrm{H}_{2} \\
\mathrm{Cu}^{2+}+2 \mathrm{e}^{-}+\mathrm{H}_{2} \mathrm{O} & \rightarrow \mathrm{CuO}+\mathrm{H}_{2}
\end{aligned}
$$

Along with the reduction of copper in the cathodic half-period, the reduction of hydrogen from water molecules occurs:

$$
2 \mathrm{H}_{2} \mathrm{O}+2 \mathrm{e}^{-} \rightarrow \mathrm{H}_{2}+2 \mathrm{OH}^{-}
$$

When copper ions and hydroxide ions interact, formed by reactions 1,2 and 5, respectively, copper hydroxides are formed by the following total reactions:

$$
\begin{aligned}
& \mathrm{Cu}^{0}+2 \mathrm{H}_{2} \mathrm{O} \rightarrow \mathrm{Cu}(\mathrm{OH})_{2}+\mathrm{H}_{2} \\
& \mathrm{Cu}^{0}+2 \mathrm{H}_{2} \mathrm{O} \rightarrow 2 \mathrm{CuOH}+\mathrm{H}_{2}
\end{aligned}
$$

Due to thermodynamic instability, copper(I) hydroxide transforms into copper(I) oxide by the reaction:

$$
2 \mathrm{CuOH} \rightarrow \mathrm{Cu}_{2} \mathrm{O}+\mathrm{H}_{2} \mathrm{O}
$$

The total process of copper electrochemical oxidation is described by the following equation: 


$$
4 \mathrm{Cu}^{0}+4 \mathrm{H}_{2} \mathrm{O} \rightarrow \mathrm{Cu}_{2} \mathrm{O}+\mathrm{CuO}+\mathrm{Cu}(\mathrm{OH})_{2}+3 \mathrm{H}_{2}
$$

During the research, it was found that the highest oxidation rate of copper electrodes in $\mathrm{NaCl}$ solution is observed within the concentration range of $0.5-1.5 \mathrm{~mol} / \mathrm{l}$. The maximum oxidation rate of the copper electrode is observed at a concentration of $1.5 \mathrm{~mol} / 1$. With an increase in the electrolyte concentration, the dissolution rate of the electrodes slightly decreases at the studied current density values. Fig.-1 shows the dissolution rates of metal electrodes at an electrolysis temperature of $50{ }^{\circ} \mathrm{C}$, depending on the current density in $\mathrm{NaCl}$ solutions at various concentrations.

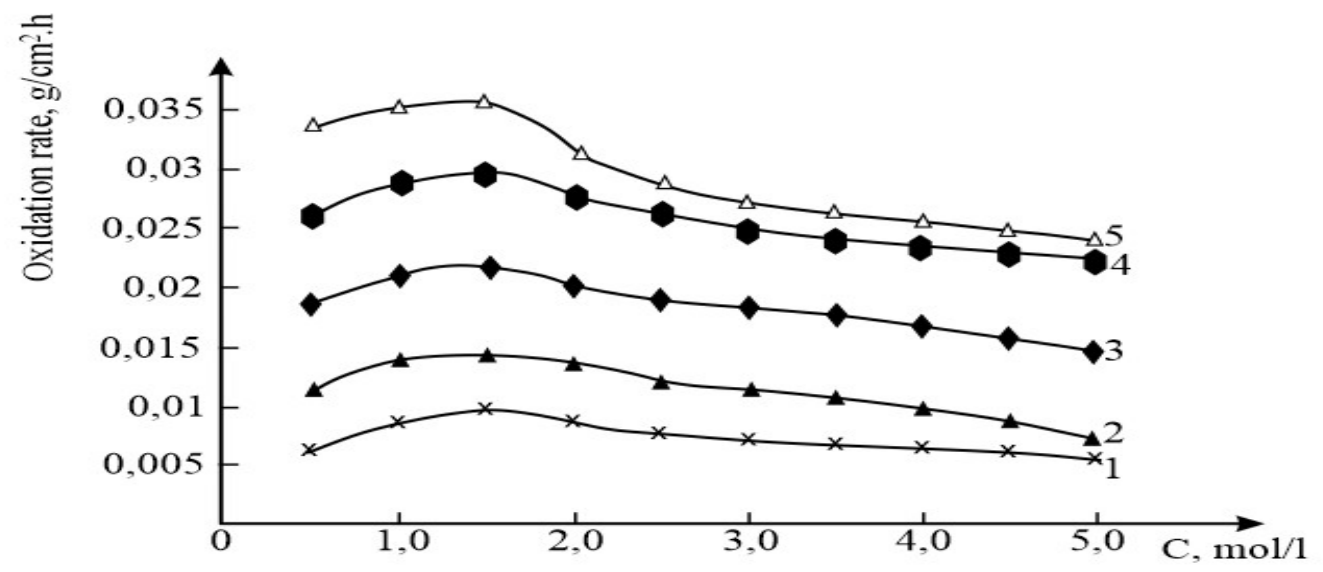

Fig.-1: Dependences of the rate of copper oxidation on the concentration of sodium chloride in solution at different current densities: $1-0.5 \mathrm{~A} / \mathrm{cm}^{2} ; 2-1.0 \mathrm{~A} / \mathrm{cm}^{2} ; 3-1.5 \mathrm{~A} / \mathrm{cm}^{2} ; 4-2.0 \mathrm{~A} / \mathrm{cm}^{2} ; 5-2.5 \mathrm{~A} / \mathrm{cm}^{2}$.

An increase in salt concentration and current density to maximum values leads to a slight increase in the rate of dissolution of electrodes, which allows us to conclude that the current density has an intensifying effect on the process of electrosynthesis of powders.

In the oxidation of metals in the absence of the possibility of any cathodic processes, except for metal reduction and hydrogen evolution, the shift of the electrode potential to the value of the hydrogen formation potential makes it possible to intensify the metal oxidation process. This can be achieved by changing the current density since with an increase in the current density, both the polarization of the electrode at the moment of changing the direction of the current and the duration of the depolarization of the electrode increase.

Fig.-2 shows the dependence of the rate of copper oxidation on the density of alternating current at a sodium chloride concentration of $1.5 \mathrm{~mol} / 1$ and a temperature range of $40-60{ }^{\circ} \mathrm{C}$.

The results of the study show that the rate of copper oxidation increases with an increase in the current density and all dependencies are linear. In the temperature range of $40-50{ }^{\circ} \mathrm{C}$, the rate of electrosynthesis is practically independent of temperature, and only when the temperature rises above $50{ }^{\circ} \mathrm{C}$, a significant increase in the oxidation rate is observed in the investigated range of current densities. The maximum value of the speed is achieved at an alternating current density of $1.5-2 \mathrm{~A} / \mathrm{cm}^{2}$, a temperature of $60{ }^{\circ} \mathrm{C}$ and is $0.038 \mathrm{~g} / \mathrm{cm}^{2} \cdot \mathrm{h}$.

The resulting suspensions of composite materials were filtered, washed repeatedly with distilled water, and dried under the influence of EMP. It was found that due to drying under the influence of EMP, the specific surface area of copper(I) oxide powder increases. By varying the parameters of electrolysis with subsequent treatment of copper(I) oxide powder with electromagnetic radiation, nanodispersed powders with a high specific surface area can be obtained.

The product of electrochemical oxidation of copper electrodes was subjected to differential thermal (DTA) and thermogravimetric analyses (TG) under the following conditions: sample weight - $115.0 \mathrm{mg}$, heating rate $-10 \mathrm{~K} / \mathrm{min}$, final temperature $-960{ }^{\circ} \mathrm{C}$. 
At temperatures up to $230{ }^{\circ} \mathrm{C}$, adsorbed moisture is removed. At the temperature range of $230-320{ }^{\circ} \mathrm{C}$, the increase in the sample mass by $2.5 \%$ of the initial mass is due to the oxidation of copper(I) oxide to copper(II) oxide.

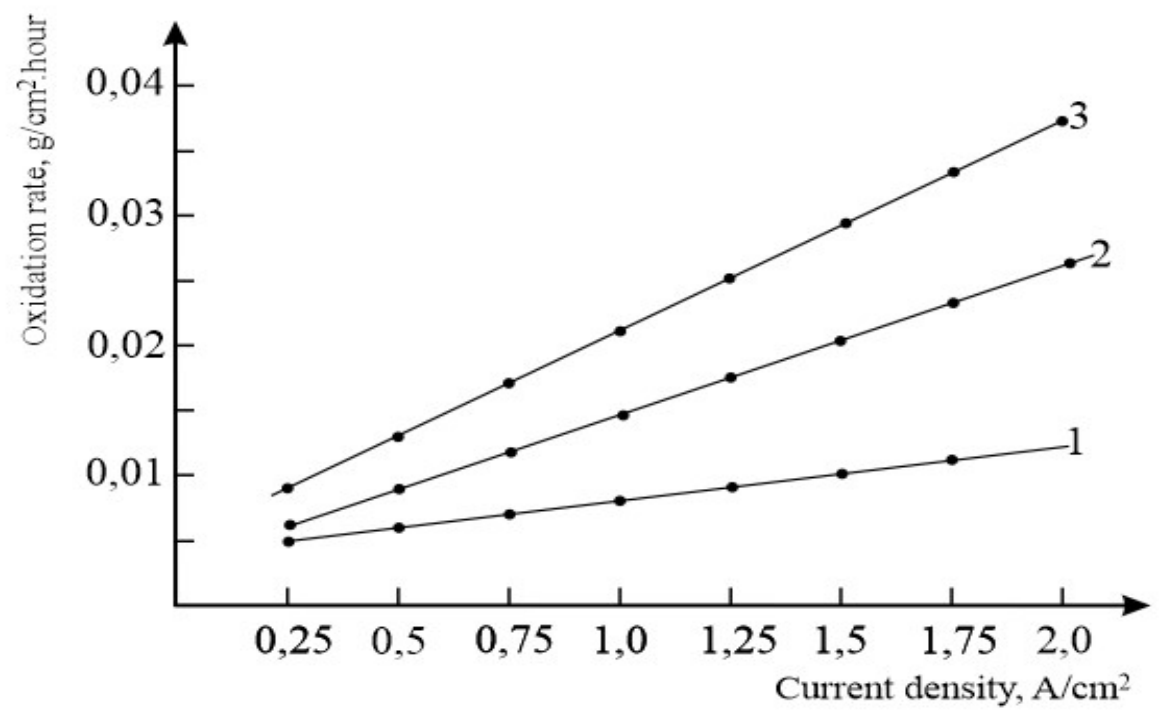

Fig.-2: Dependences of the rate of copper oxidation on the current density at various temperatures and sodium chloride concentration of $1.5 \mathrm{~mol} / \mathrm{l}: 1-40{ }^{\circ} \mathrm{C} ; 2-50{ }^{\circ} \mathrm{C} ; 3-60{ }^{\circ} \mathrm{C}$

The results of the analysis indicate that in the indicated temperature range, all $\mathrm{Cu}_{2} \mathrm{O}$ is oxidized to $\mathrm{CuO}$. The exothermic effect corresponding to this process manifests itself against the background of a wide exothermic effect of crystallization and recrystallization of copper(I) oxide. Thus, it was found that the electrooxidation of copper under the action of an alternating current allows one to obtain $\mathrm{Cu}_{2} \mathrm{O}$, which is formed at much lower temperatures than copper(I) oxide.

The results of the performed X-ray phase analysis (Fig.-3) determined that the only crystalline phase of the electrolysis product is copper(I) oxide. This is evidenced by reflexes corresponding to interplanar distances equal to: $0.301 ; 0.244 ; 0.151 ; 0.129 \mathrm{~nm}$. Comparing the results obtained, it can be concluded that the electrosynthesis product is a mixture of oxides and hydroxide of copper(II), formed according to the overall equation (9), while the latter are not recorded by XRD, since they are in an X-ray amorphous state. Based on the results of DTA, copper(II) hydroxide is dehydrated to form copper(II) oxide, and the effect of EMR completes the process of removing crystallization water, which allows us to conclude that the XRD data are reliable.

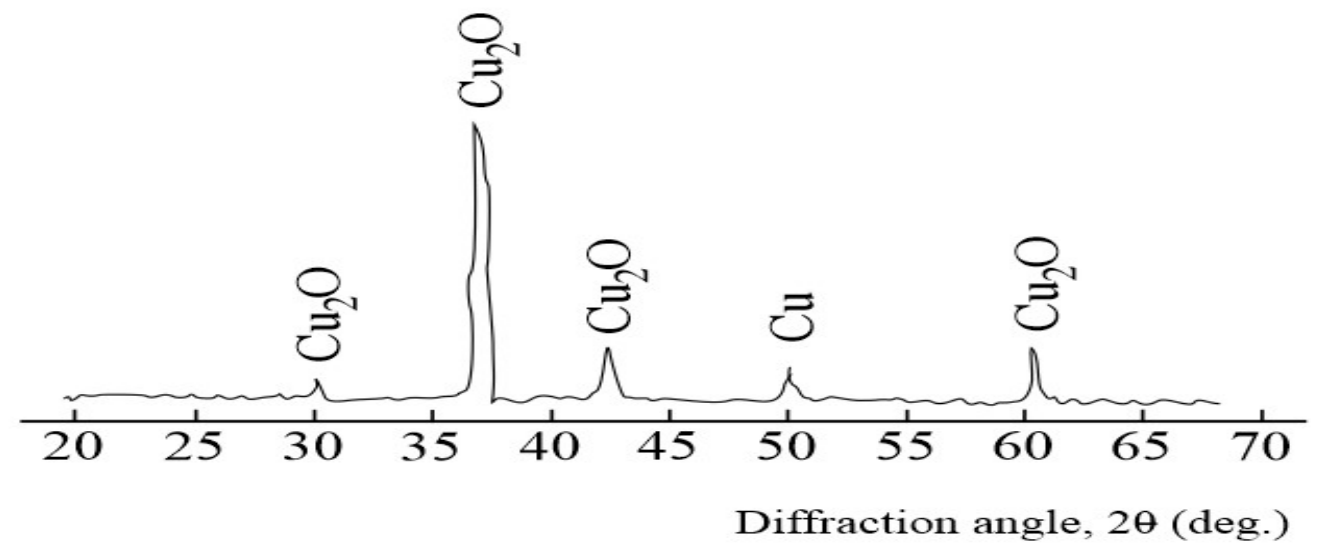

Fig.-3: X-ray diffraction pattern of the product synthesized by electrochemical oxidation of metallic copper 


\section{RASĀYAN J. Chem.}

Vol. 14 | No. 3 |2040-2047| July - September | 2021

To study the morphology of microcrystals of copper(I) oxide powder and determine the size of particles formed during the electrochemical dissolution of copper electrodes on alternating current, electron microscopic studies of the electrolysis product were carried out. Micrographs obtained by electron microscopic analysis are shown in Fig.-4. As can be seen from the micrographs, the particles have different shapes. Some particles are round and assembled into aggregates, while others are irregularly shaped. At magnification (x5000, Fig. $-4, \mathrm{~b}$ ), the size of aggregated spherical nanoparticles is smaller than that of particles with an irregular geometric shape and is $5-15 \mathrm{~nm}$.

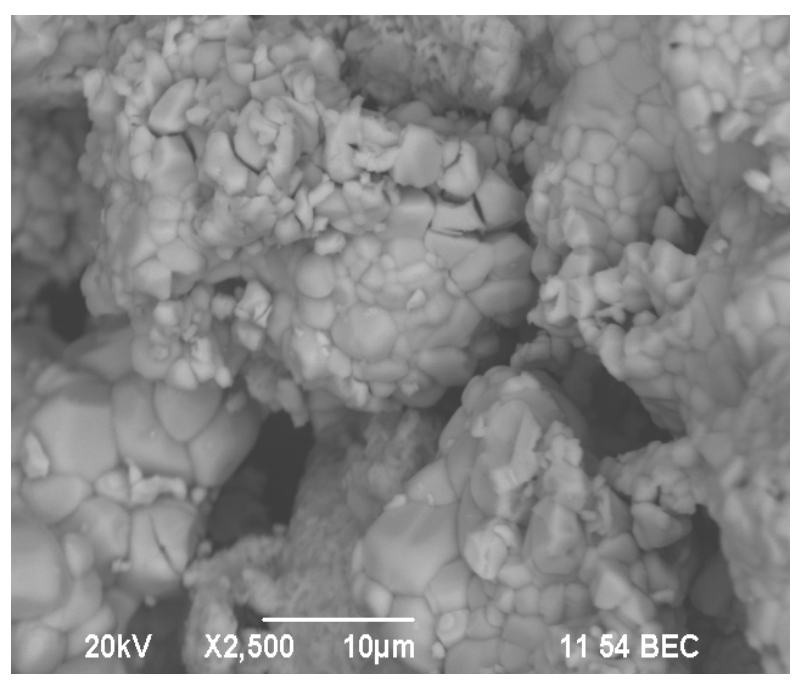

a

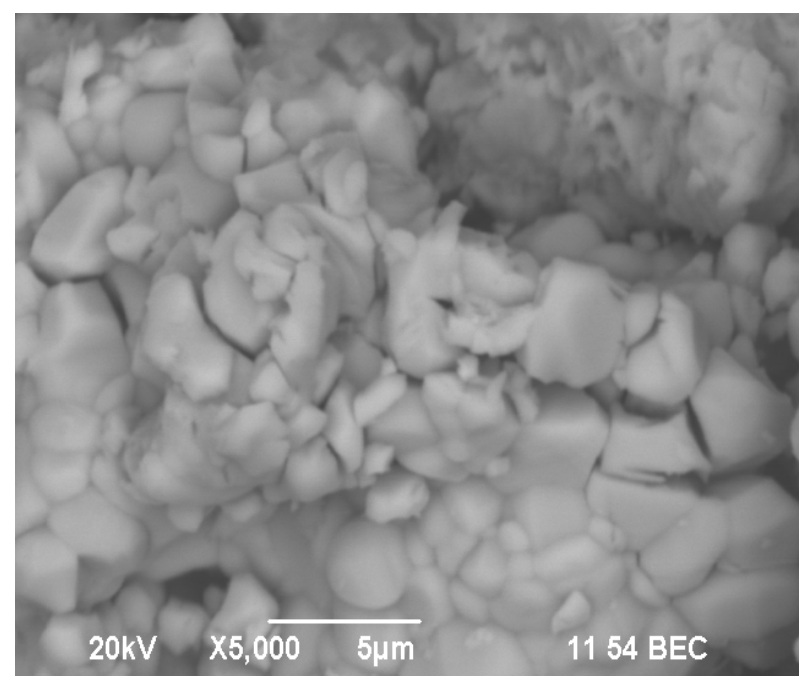

b

Fig.- 4: Micrographs of copper(I) oxide powder obtained by electrolysis in $\mathrm{NaCl}$ solution of $1.5 \mathrm{~mol} / \mathrm{l}$ and a current density of $1.5 \mathrm{~A} / \mathrm{cm}^{2}: \mathrm{a}-\mathrm{x} 2500 ; \mathrm{b}-\mathrm{x} 5000$.

The elemental composition of copper(I) oxide powder obtained by electrolysis in $\mathrm{NaCl}$ solution of 1.5 $\mathrm{mol} / 1$ and a current density of $1.5 \mathrm{~A} / \mathrm{cm}^{2}$ is shown in Fig.-5.

\begin{tabular}{c|c}
\hline Elements & Weight, \% \\
\hline $\mathrm{C}$ & 1.83 \\
\hline $\mathrm{O}$ & 1.05 \\
\hline $\mathrm{Al}$ & 0.17 \\
\hline $\mathrm{Cu}$ & 96.94 \\
\hline
\end{tabular}

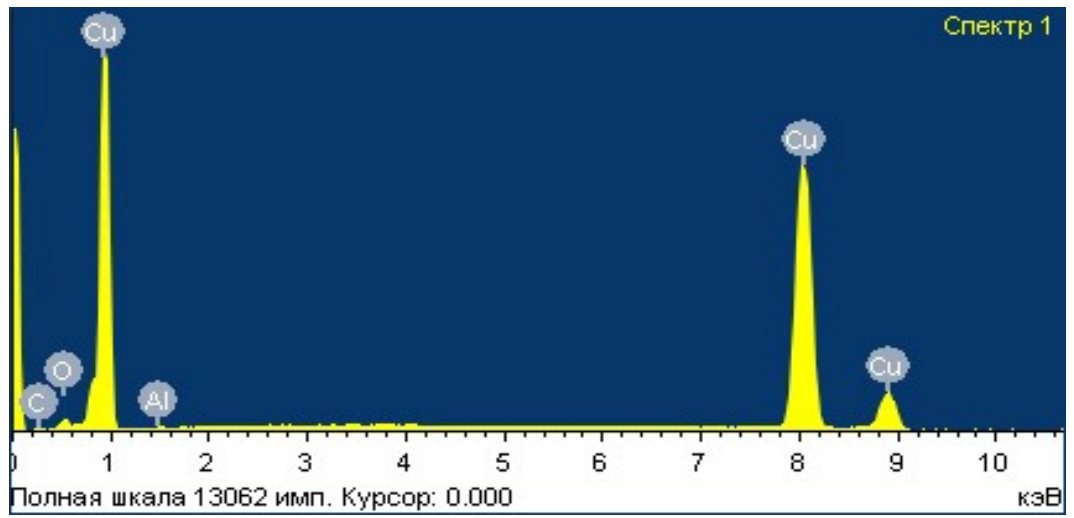

Fig.- 5: Elemental composition of copper(I) oxide powder obtained by electrolysis in $\mathrm{NaCl}$ solution of $1.5 \mathrm{~mol} / \mathrm{l}$ and a current density of $1.5 \mathrm{~A} / \mathrm{cm}^{2}$

For samples obtained by varying the concentration of sodium chloride, current density, electrolysis temperature and having different phase compositions, the specific surface area $S_{\mathrm{sp}}$ was measured by the BET method. The dispersion and specific surface area of the oxidation products of copper electrodes under the influence of alternating current depend on the current density - the main parameter that intensifies the process of electrosynthesis of copper(I) oxide powder. 
The microporous structure of copper(I) oxide formed during electrosynthesis undergoes even more significant changes in the course of additional processing using EMP. This is primarily due to the variation in pore sizes, total volume, and specific surface area $\left(\mathrm{S}_{\mathrm{sp}}\right)$. The specific surface area is an important characteristic that determines the main performance properties of copper(I) oxide.

The IR spectrum of copper(I) oxide obtained by electrolysis in $\mathrm{NaCl}$ solution of $1.5 \mathrm{~mol} / \mathrm{L}$ and a current density of $1.5 \mathrm{~A} / \mathrm{cm}^{2}$ is shown in Fig.-6. The absorption band with a frequency of $671.23 \mathrm{~cm}^{-1}$ is due to stretching vibrations $v_{\mathrm{Cu}-\mathrm{O}}$ in the copper(I) oxide lattice. In addition, in the $1100-3000 \mathrm{~cm}^{-1}$ region, additional very weak absorption bands are observed, which can be considered as vibrations of groups formed on the surface as a result of the interaction of oxygen atoms with surface copper cations, which have a lower coordination oxygen unsaturation.

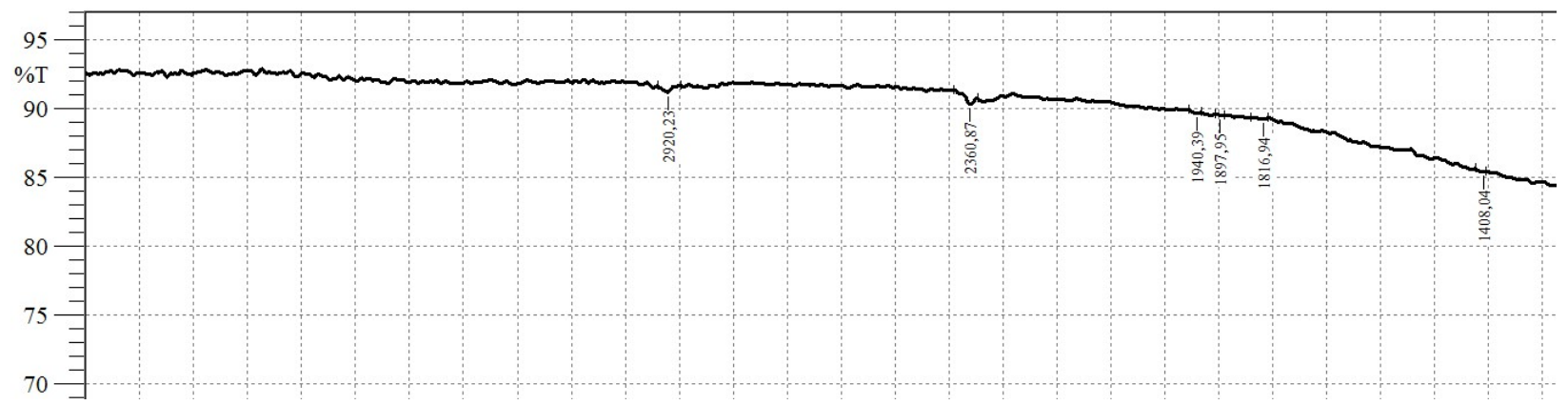

Fig.-6: IR spectrum of the product obtained by electrolysis in $\mathrm{NaCl}$ solution of $1.5 \mathrm{~mol} / \mathrm{l}$ and a current density of $1.5 \mathrm{~A} / \mathrm{cm}^{2}$

The largest values of the specific surface area $\left(29.5 \mathrm{~m}^{2} / \mathrm{g}\right)$ correspond to copper(I) oxide obtained at a sodium chloride concentration of $3.0-3.5 \mathrm{~mol} / \mathrm{l}$, a current density of $1.5-1.75 \mathrm{~A} / \mathrm{cm}^{2}$ and temperature $55{ }^{\circ} \mathrm{C}$, power of exposure to EMR - 1000-1200 W, exposure time 5 minutes. The particle size of the copper(I) oxide powder obtained under these conditions is $5-10 \mathrm{~nm}$. With an increase in the current density to $2-2.5 \mathrm{~A} / \mathrm{cm}^{2}$ and an electrolyte concentration of more than $3.5 \mathrm{~mol} / \mathrm{L}$, the specific surface area of the copper(I) oxide powder decreases to $15.3-17.1 \mathrm{~m}^{2} / \mathrm{g}$ and, accordingly, the particle size of the powder increases to $25-30 \mathrm{~nm}$.

\section{CONCLUSION}

Thus, carrying out the electrolysis process using an alternating current of an industrial frequency of $50 \mathrm{~Hz}$ allows for the electrochemical dissolution of copper electrodes in sodium chloride solutions.

By varying the concentration of electrolytes, the current density at low electrolysis temperatures, followed by the effect of electromagnetic radiation on the copper(I) oxide powder, it is possible to obtain nanodispersed powders with a high specific surface area of $27.1-29.5 \mathrm{~m}^{2} / \mathrm{g}$ and a particle size of 5-10 nm. The use of electromagnetic radiation instead of the processes of drying and heat treatment of the powder after the electrolysis process leads to a reduction in energy costs and time for carrying out the processes of copper(I) oxide synthesis.

\section{ACKNOWLEDGEMENT}

This research is funded by the Science Committee of the Ministry of Education and Science of the Republic of Kazakhstan (Grant No. AP08956404 «Development of a method for producing nano- and micro-sized dispersed materials based on copper and zinc oxides by electrolysis under non-stationary conditions»).

\section{REFERENCES}

1. A.S. Dolinina, V.V. Korobochkin, N.V. Usoltseva, S.E. Pugacheva, M.V. Popov, Procedia Chemistry, 15, 143(2015), https://doi.org/10.1016/j.proche.2015.10.023

2. K. Iskakova, R. Akhmaltdinov, O. Mamyrbayev, AIMS Materials Science, 6(3), 54(2019), https://doi.org/10.3934/matersci.2019.3.454 
RASĀYAN J. Chem.

Vol. 14 | No. 3 |2040-2047| July - September | 2021

3. G. Helen Annal Therese, P. Vishnu Kamath, Chemistry of Materials, 12(5), 1195(2000), https://doi.org/10.1021/cm990447a

4. A.S. Kolesnikov, Russian Journal of Non-Ferrous Metals, 56(1), 1(2015), https://doi.org/10.3103/S1067821215010113

5. A.S. Kolesnikov, V.N. Naraev, M.I. Natorhin, A.A. Saipov, O.G. Kolesnikova, Rasayan Journal of Chemistry, 13(4), 2420(2020), https://doi.org/10.31788/RJC.2020.1346102

6. X. Zhang, Y. Zhang, J. Xu, Wang Z., et al., Applied Physics Letters, 87(12), 123(2005), https://doi.org/10.1063/1.2053370

7. V.V. Korobochkin, N.V. Usoltseva, D.A. Balmashnov, A.S. Dolinina, Procedia Chemistry, 10, 369(2014), https://doi.org/10.1016/j.proche.2014.10.062

8. A.S. Kolesnikov, I.V. Sergeeva, N.E. Botabaev, A.Zh. Al'zhanova, Kh.A. Ashirbaev, Steel in Translation, 47, 605(2017), https://doi.org/10.3103/S0967091217090078

9. Zh. I. Bespalova, A.V. Khramenkova, Nanosistems: Physics, Chemistry, Mathematics, 7(3), 433(2016), https://doi.org/10.17586/22208054201673433450

10. P. Ram Sankar, P. Tiwari, R. Kumar, T. Ganguli, et al., Applied Surface Science, 256, 2097(2010).

11. N.V. Usoltseva, V.V. Korobochkin, M.L. Balmashnov, L.Z. Dolinina, Procedia Chemistry, 15, 84(2015), https://doi.org/10.1016/j.proche.2015.10.013

12. A.B. Kilimnik, E. Y. Nikiforova, Russian Journal of Electrochemistry, 49(12), 1122(2013), https://doi.org/10.1134/S1023193513120033

13. K. Raju, D. H. Yoon, Materials Letters, 110, 188(2013), https://doi.org/10.1016/j.matlet.2013. 08.037

14. Aigul Mamyrbekova, B.S. Abzhalov, Aizhan Mamyrbekova, Russian Journal of Physical Chemistry A, 91(7), 1332(2017), https://doi.org/10.1134/S0036024417070226

15. M.K. Kassymova, M. K. Nauryzbaev, Aigul' Mamyrbekova, G. N. Zhylysbayeva, Aizhan Mamyrbekova, Russian Journal of Physical Chemistry A, 93(5), 980(2019), https://doi.org/10.1134/S0036024419050170

16. A. Ananth, S. Dharaneedharan, M.-S. Heo, Y. S. Mok, Chemical Engineering journal, 262, 179(2015). https://doi.org/10.1016/j.cej.2014.09.083

17. A. Dolinina, V. Korobochrin, N. Usoltseva, I. Frolova, M. Popov, Key Engineering Materials, 743, 292(2017), https://doi.org/10.4028/www.scientific.net/KEM.743.292

18. A. S. Dolinina, V.V. Korobochkin, N.V. Usoltseva, E.A. Bikbayeva, M.V. Popov, Key Engineering Materials, 712, 112(2016), https://doi.org/10.4028/www.scientific.net/KEM.712.112

19. Z. Galus, 1974, Theoretical foundations of electrochemical analysis, Publishing Mir, Moscow, pp.254-297.

20. V.I. Gorokhovskaya, V. M. Gorokhovskyy, 1983, Practicum on electrochemical methods of analysis. Publishing Higher School of Economics, Moscow, pp. 130-140.

21. T. N. Ostanina, V. M. Rudoy, V. S. Nikitin, A. B. Darintseva, S. L. Demakov, Journal of Electroanalytical Chemistry, 784(12), 13(2017), https://doi.org/10.1016/j.jelechem.2016.11.063

22. B.B. Damaskin, O.A. Petryy, G.A. Tsirlina, 2006, Publishing Chemistry, Electrochemistry, Moscow, pp. 124-135.

23. J. Gomez Becerra, R. C. Salvarezza, A. J. Arvia, Electrochimica Acta, 33(5), 613(1988), https://doi.org/10.1016/0013-4686(88)80059-8

[RJC-6384/2021] 